\title{
Observations on the pathogenesis of chronic airflow obstruction in smokers: implications for the detection of "early" lung disease
}

Cigarette smoking causes various pathological changes in the lungs, some of which may lead to chronic airflow obstruction, which is an important cause of respiratory morbidity and mortality. The changes attributable to smoking include large airway effects (mucous gland enlargement and mucous hypersecretion, smooth muscle hypertrophy, atrophy of bronchial walls); small airway changes (bronchiolar inflammation, fibrosis, ulceration, and tortuousity, with diffuse narrowing of the airways); and pulmonary emphysema. ${ }^{1-5}$ The relative roles of these pathological features in causing chronic airflow obstruction have been examined and two hypotheses for its pathogenesis in smokers have been proposed.

The most common condition associated with chronic airflow obstruction in smokers is emphysema, which is usually of the centrilobular type, although mixtures of centrilobular and panlobular changes are also found. ${ }^{34}$ One current concept of the pathogenesis of emphysema is based on an imbalance between proteases and antiproteases in the lung parenchyma; $^{6-8}$ a relative excess of proteases, particularly elastases, is thought to occur in the lungs of many smokers, and this may promote the disruption of connective tissue fibres. Because the tissue fibre network is essential for the structural integrity of alveoli, proteolytic activity can lead to disruption of alveolar walls and alveolar enlargement. ${ }^{9-11}$ Alveolar enlargement leads to decreased lung elasticity and decreased elastic support of the airway walls. ${ }^{12} 13$ The resulting decrease in elastic driving pressure and increased likelihood of expiratory airway collapse is responsible, in turn, for decreased maximum expiratory airflow from the lungs and the characteristic spirometric pattern of chronic airflow obstruction. ${ }^{1415 *}$ This hypothesis for the development of

*Airflow obstruction 4 is defined typically as a decreased $\mathrm{FEV}_{1}$ (that
is, a value less than $80 \%$ of that predicted) in the presence of a
proportionately smaller decrease in forced vital capacity. As we shall
show below, a decreased $\mathrm{FEV}_{1}$ has poor sensitivity for predicting the
presence of emphysema.

Address for reprint requests: Dr Ian A Greaves, Department of Environmental Science and Physiology, Harvard School of Public Health, 665 Huntington Avenue, Boston, Massachusetts 02115, USA. chronic airflow obstruction in smokers emphasises the parenchymal effects of smoking in producing emphysema and loss of lung elasticity.

An alternative view is that pathological changes in the "small airways" (defined as airways less than $2 \mathrm{~mm}$ in internal diameter, principally the terminal and respiratory bronchioles) are either the major sites of airflow obstruction ${ }^{16-18}$ or an important intermediate step in the pathogenesis of emphysema, which is then responsible for chronic airflow obstruction. $18-22$

The relative merits of these two hypotheses have not been tested, but they can be assessed from the published data of Mitchell and coworkers, ${ }^{3}$ who described the post mortem features of emphysema and "small airway" pathology in relation to cumulative smoking exposure (expressed as pack years), and in relation to the presence and severity of chronic airflow obstruction assessed shortly before death. Mitchell and colleagues observed that "pathologic changes in large and small airways in the absence of much emphysema were very seldom associated with chronic airflow obstruction," but nonetheless they considered that the data were "consistent with a growing consensus that loss of small airway support by surrounding lung tissue in emphysema may cause kinking, tortuousity, and collapse of the airways, with subsequent increased airflow resistance and clinical obstruction". 3

If a causal relationship exists between small airway pathology and emphysema or if small airway pathlogy were responsible for chronic airflow obstruction in smokers, highly significant associations between small airway pathlogy and emphysema, or between small airway pathlogy and chronic airflow obstruction, should be present in the data of Mitchell and coworkers. Further examination of their findings, however, shows no strong association, after cumulative smoking has been allowed for, between small airway pathlogy and either emphysema or chronic airflow obstruction. The prevalence rates of emphysema, small airway pathlogy and emphysema plus small airway pathlogy are shown for the total group of lungs studied by Mitchell et al (table 1), and the findings have been stratified into three smoking 
Table 1 Presence of emphysema and of "small airway"pathology (SAP) in postmortem lungs grouped according to lifetime cigarette consumption (data from Mitchell et al $^{3}$ )

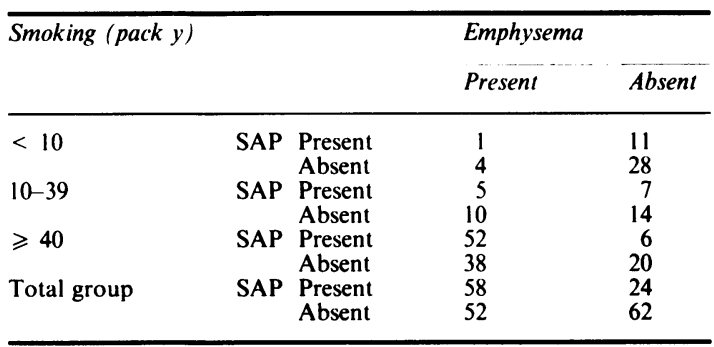

groups: those who had smoked less than 10, 10-39, and $\mathbf{4 0}$ or more pack years. Mitchell and coworkers used a 100 point grading system to assess the extent of emphysema, and they considered mainly moderate to severe emphysema (grades $\geqslant 30$ ). Small airway pathology was classified according to the presence and severity of chronic inflammation, goblet cell metaplasia, and mural fibrosis in the peripheral airways. As cumulative smoking increased, the prevalence of emphysema increased from $11 \%$ to $41 \%$ to $78 \%$, and the prevalence of small airway pathology also increased-from $25 \%$ to $33 \%$ to $50 \%$ (table 1 ). These findings show an exposure-response relationship for both emphysema and small airway pathology with cumulative smoking. Since the likelihood of either emphysema or small airway pathology increases with the amount smoked, it follows that the chance association of the two conditions also increases with smoking, because the expected occurrence by chance of emphysema plus small airway pathology is equal to the product of the probabilities (prevalences) of emphysema and of small airway pathology. In this case the expected prevalence of emphysema plus small airway pathology for increasing cigarette consumption is $3 \%, 14 \%$, and $39 \%$, compared with the observed rates of $2 \%, 14 \%$, and $45 \%$ respectively.

An important conclusion from these findings is that the cumulative smoking history is a very strong determinant of the prevalence both of emphysema and of small airway pathology, and therefore of the association between emphysema and small airway pathology. In other words, quite apart from any causal relationship between small airway pathology and emphysema, cumulative smoking has a major influence on the chance association between the twc conditions. Failure to account for the confounding effect of cumulative smoking may therefore bias tests of association between small airway pathology and emphysema so that a spurious association may be found.
These calculations of the observed and expected rates for emphysema plus small airway pathology in the various smoking categories show that only in the highest smoking group ( $\geqslant 40$ pack years) is there an excess of people with both emphysema and small airway pathology. A major proportion $(59 \%)$ of the total observations, however, lies in this open ended high exposure category. This raises the possibility of inadequate control for confounding by smoking in this group, which could have resulted in a spurious excess of people with both emphysema and small airway pathology in this category. Such a spurious result would be amenable to testing in the original data by further stratifying the high smoking group, but unfortunately the data are no longer in an analysable form (RS Mitchell, personal communication).

Further features of Mitchell's data suggest that the above interpretation is probably correct. When the findings are analysed according to either the absence or the presence of severe chronic airflow obstruction that was thought to cause death (table 2), the prevalence of emphysema was $17 \%$ and $99 \%$ and the prevalence of small airway pathology was $29 \%$ and $59 \%$. The resulting expected rates for emphysema plus small airway pathology were very similar to the observed values $(5 \%$ and $59 \%$ versus $7 \%$ and $59 \%$ respectively).

Among Mitchell's subjects who died from chronic airflow obstruction, emphysema was found in the lungs of all but one, whereas small airway pathology occurred in only $59 \%$ of the same group (table 2), emphasising the greater importance of emphysema in determining chronic airflow obstruction in this study population. The distribution of emphysema grades for those dying with or without evidence of chronic airflow obstruction is shown in figure 1 . On a scale of zero to 100 all of those dying from chronic airflow obstruction had emphysema grades of 35 or higher, while only 11 of $87(12 \%)$ of those without chronic airflow obstruction had similar high grades of emphysema. Those who were classified as having "disabling" or "suspect mild" chronic airflow obstruction had proportions of high grade

Table 2 Presence of emphysema and of "small airway" pathology $(S A P)$ in postmortem lung specimens with respect to the presence or absence of severe chronic airflow obstruction (CAO) thought to have caused death (data from Mitchell et $\mathrm{al}^{3}$ )

\begin{tabular}{|c|c|c|c|c|}
\hline \multirow[t]{2}{*}{$C A O$} & & & \multicolumn{2}{|c|}{ Emphysema } \\
\hline & & & Present & Absent \\
\hline $\begin{array}{l}\text { No CAO } \\
\text { CAO caused death }\end{array}$ & $\begin{array}{l}\text { SAP } \\
\text { SAP }\end{array}$ & $\begin{array}{l}\text { Present } \\
\text { Absent } \\
\text { Present } \\
\text { Absent }\end{array}$ & $\begin{array}{r}6 \\
9 \\
38 \\
26\end{array}$ & $\begin{array}{r}19 \\
53 \\
1 \\
0\end{array}$ \\
\hline
\end{tabular}



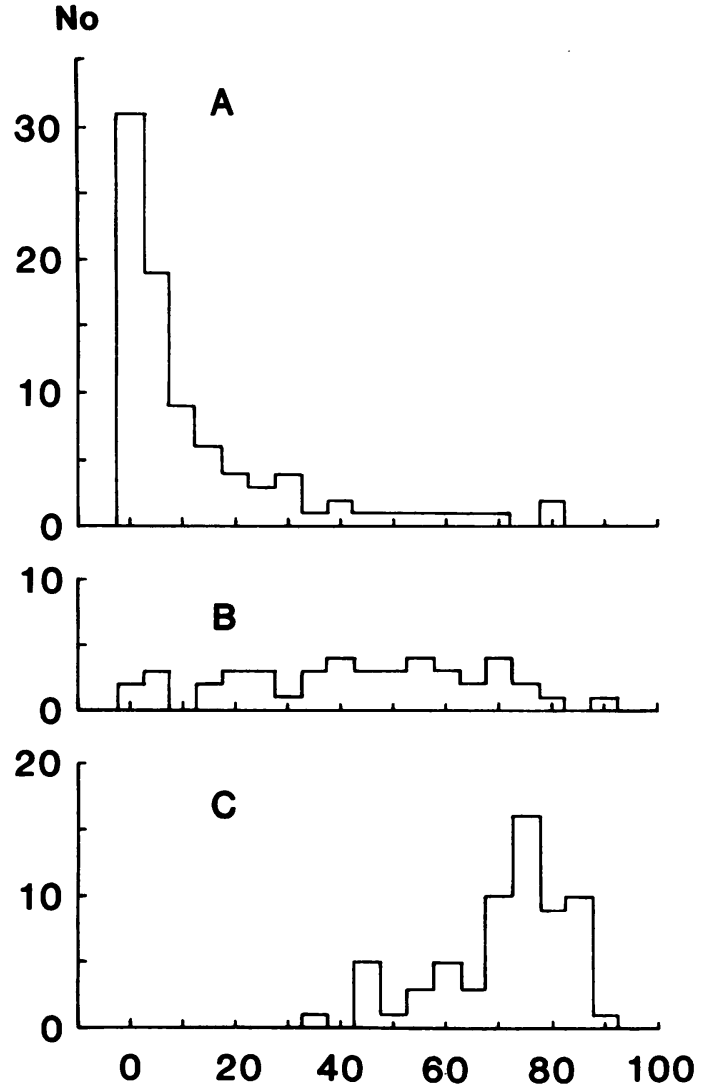

EMPHYSEMA GRADE

Fig 1 Frequency histogram of emphysema grades redrawn from the data of Mitchell et al. ${ }^{3}(A)$ Subjects without clinical chronic airflow obstruction $(n=87)$. (B) Subjects with chronic airflow obstruction of a degree that did not cause death $(n=44)$. (C) Subjects with chronic airflow obstruction that caused their death $(n=65)$.

emphysema that were intermediate between the proportions in those without chronic airflow obstruction and those dying from it (fig 1).

This is not to say that small airway pathology, or for that matter large airway disease, is irrelevant to airflow obstruction in a proportion of smokers. Indeed, there is experimental evidence that small airway pathology in the presence of emphysema has a greater than additive effect in producing airflow obstruction, ${ }^{23}$ and postmortem studies in man show that intrinsic airway narrowing contributes to limitation of expiratory airflow in emphysematous lungs. ${ }^{24}$ "Pure" intrinsic airway narrowing causing severe chronic airflow obstruction is an unusual finding in smokers. Patients with severe chronic airflow obstruction due to "primary bronchial dis- ease" 25 are found occasionally, but the usual physiological findings in subjects with disabling chronic airflow obstruction suggest a combination of emphysema and intrinsic airway narrowing. This observation may simply reflect the fact that the two conditions together produce greater airflow limitation than either alone, and that more severely disabled individuals are more likely to come to a physician's attention.

Partly to address this issue of end stage chronic airflow obstruction versus less disabling disease, Hale and coworkers ${ }^{26}$ recently compared the relative contributions of emphysema and small airway pathology in smokers with severe airflow obstruction and in a group of non-smokers and a group of smokers without severe pulmonary disease who died outside hospital. Two thirds of smokers dying with severe chronic airflow obstruction had emphysema of $\mathbf{3 0}$ or more units, compared with $12 \%$ of smokers without severe lung disease and 7\% of non-smokers. Premortem $\mathrm{FEV}_{1}$ measurements correlated more closely with the severity of emphysema (determined by inspection of lung slices) than with the severity of small airway pathology (determined histologically). The authors concluded that among smokers with chronic airflow obstruction "no morphologic or pathologic feature of the small airways was an independent predictor of ventilatory function beyond that of emphysema alone." ${ }^{26}$ The findings confirm those of Mitchell et $a l^{3}$ and earlier workers, ${ }^{12}$ but in the absence of quantitative information on smoking we cannot determine whether the data of Hale and colleagues show independent contributions or interactions between emphysema and small airway pathology in producing chronic airflow obstruction.

Additional support for the independent occurrence of small airway pathology and emphysema comes from morphological studies showing that the distribution of small airway pathology in the upper and lower lung lobes does not parallel the distribution of emphysema in the same lungs. ${ }^{27} 28$ The lack of a morphological association between small airway pathology and emphysema suggests that the two either are determined by different host responses to a common agent or are responses to different components of cigarette smoke. In either case the pathological findings suggest that small airway pathology and emphysema are not causally related.

The studies of lung pathology are pertinent to the development of chronic airflow obstruction and the question of how "early" (subclinical) changes in lung function might be recognised. As a general principle, it seems desirable to have some means whereby affected individuals may be identified at a stage when the changes in their lungs might be reversible, or at least limited at the earliest possible stage, even if 
attempts to persuade smokers to quit smoking have been largely unrewarding. ${ }^{18} 29$ Moreover, greater understanding of "early" smoking effects would possibly help to define a subgroup of the general population who are particularly susceptible to chronic airflow obstruction from smoking and other agents. One candidate for such "early" change would be an asymptomatic increase in lung distensibility, indicative of mild emphysema (see below), with an increased risk of chronic airflow obstruction due either to progression of emphysema or to development of intrinsic airway narrowing in addition. Furthermore, knowledge of the "early" effects of smoking may help to distinguish changes attributable to smoking from those caused by exposure to other air contaminants, such as those occurring in the workplace.

Because small airway pathology is a poor predictor of which smokers may have emphysema and possibly progress to disabling chronic airflow obstruction, attention should be directed more to tests that indicate the presence of mild or "early" emphysema. Measures of lung function in individuals before lung resection 203031 and in postmortem lungs ${ }^{1232-35}$ have shown that elastic recoil changes correlate better than other lung function tests with the presence and severity of emphysema. Decreased elastic recoil pressures and increased lung distensibility, with an accompanying increase in total lung capacity (TLC) and functional residual capacity (FRC), have been found even in mildly emphysematous lungs. ${ }^{11} 24-2631-35$

An exponential function of the general form $V=\mathrm{A}$ - $\mathrm{Be}^{-\mathrm{KP}}$ (where $V$ is lung volume, $\mathrm{P}$ is static recoil pressure, and $\mathrm{A}, \mathrm{B}$, and $\mathrm{K}$ are constants) has been found useful in describing the static deflation pressure-volume (PF) curve. ${ }^{12132536-38}$ The constant $\mathrm{K}$ in this expression has important biological significance: it is an index of lung distensibility that describes the shape of the pressure-volume curve over the upper half of lung volume, and it is inversely related to the bulk elastic modulus of the lungs, ${ }^{13}$ it is influenced mainly by the density of surface tension forces within the lungs and these, in turn, are directly related to the alveolar surface to volume ratio, which is determined by the mean size of peripheral air spaces. ${ }^{1213}$ Because the distinguishing feature of emphysema is alveolar enlargement accompanied by disruption of the parenchymal fibre network, it is not surprising that an increase in $\mathrm{K}$ correlates closely with the presence and severity of readily ventilated emphysematous regions. ${ }^{1231}$

That the constant $K$ is the single best predictor of emphysema has been reported by Paré and coworkers, ${ }^{31}$ whose data also provide estimates for the sensitivity, specificity, and predictive values ${ }^{39}$ of various standard lung function tests (maximum expiratory flow-volume curves, lung volumes, gas transfer factor, and $P V$ curves) that are used to determine the nature and severity of chronic airflow obstruction (table 3). In this study lung function measurements were obtained from patients shortly before lung resections were performed for cancer; the morphological features of the resected specimens were then compared with the preoperative lung function findings. As pointed out by Paré et al, there is a possibility of sampling error in the assessment of structural changes on the basis of small specimens, but the effects of sampling error are probably small when emphysema grades are classified as either 15 or less or greater than 15 . The overall prevalence of emphysema grades greater than 15 was 16 out of 55 cases $(29 \%)$. Tests showing high sensitivity for emphysema were an increased value for the exponential constant $\mathrm{K}$ and an increased TLC or FRC. Tests having a high specificity included an increased value of $\mathrm{K}$, a decreased gas transfer factor (single breath diffusing capacity for carbon monoxide), a decreased maximum inspiratory pressure, and a decreased $\mathrm{FEV}_{1}$.

Table 3 Sensitivities, specificities, and predictive values for selected lung function tests in predicting the presence of emphysema (grades over 15) in resected lung specimens.* (values calculated from the results of Paré et $\mathrm{al}^{31}$ )

\begin{tabular}{|c|c|c|c|c|}
\hline Abnormal result & Sensitivity (\%) & Specificity (\%) & $\begin{array}{l}\text { Predictive value } \\
\text { positive }(\%)\end{array}$ & $\begin{array}{l}\text { Predictive value } \\
\text { negative }(\%)\end{array}$ \\
\hline $\begin{array}{l}\text { Increased K } \\
\text { Decreased PLmi } \\
\text { Decreased PL90 } \\
\text { Decreased PL60 } \\
\text { Decreased TLCO } \\
\text { Decreased FEV } \\
\text { Decreased FEF }_{50} \\
\text { Increased TLC } \\
\text { Increased FRC }\end{array}$ & $\begin{array}{r}69 \\
0 \\
38 \\
19 \\
38 \\
13 \\
44 \\
56 \\
75\end{array}$ & $\begin{array}{l}87 \\
92 \\
82 \\
80 \\
95 \\
90 \\
80 \\
67 \\
56\end{array}$ & $\begin{array}{r}69 \\
0 \\
46 \\
27 \\
75 \\
33 \\
47 \\
41 \\
41\end{array}$ & $\begin{array}{l}87 \\
69 \\
76 \\
71 \\
79 \\
71 \\
78 \\
79 \\
85\end{array}$ \\
\hline
\end{tabular}

*For definitions of sensitivity, specificity, and predictive values see ref 39.

$\mathrm{K}$ - the exponential constant in V $=\mathrm{A}-\mathrm{Be}^{-\mathrm{KP}}$ (see text); PLmi, PL90, PL60-static recoil pressures at maximal infiation, $90 \%$, and $60 \%$ of total lung capacity; TLCO-gas transfer factor (single breath diffusing capacity for carbon monoxide); FEF ${ }_{\text {so }}-$ the maximum expiratory flow at $50 \%$ of forced vital capacity; TLC - total lung capacity; FRC-functional residual capacity. 
Overall, the tests having the highest predictive values were found for an increased $\mathrm{K}$ and a decreased gas transfer factor (table 3). This result is perhaps to be expected because it can be shown on theoretical grounds that the exponential constant $\mathbf{K}$ and the gas transfer factor are inversely related through the dependence of each test on the alveolar surface to volume ratio (mean size of alveoli); studies on human subjects have shown a relationship between $1 / \mathrm{K}$ and gas transfer factor. ${ }^{40}$ The findings of Pereira and coworkers ${ }^{41}$ and earlier studies confirm that substantial changes in lung distensibility and gas transfer factor occur in subjects with emphysema, but not in those with exclusively airway disease.

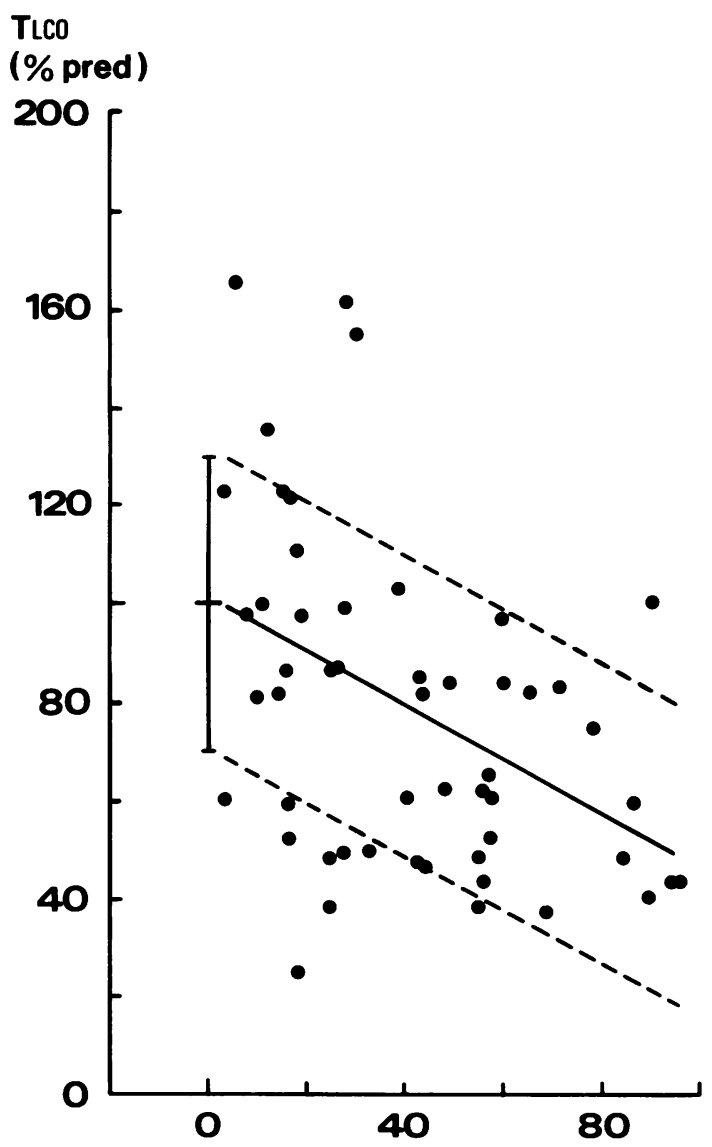

$\%$ Emphysema

Fig 2 Regression of steady state gas transfer factor (TLCO), expressed as a percentage of the predicted normal value, on emphysema grade $\left(r^{2}=0.19\right)$. Bars indicate one standard deviation. Data from Thurlbeck et al. ${ }^{42}$
In an earlier study by Thurlbeck and colleagues ${ }^{\mathbf{4}}$ steady state diffusing capacity (transfer factor) measurements showed a significant decrease with increasing emphysema grades, but there was considerable variability (fig 2). Among subjects with "mild" emphysema (grades 5-20), transfer factor was less than $80 \%$ of the predicted normal in four of 16 cases (25\%), while for "moderate" (grades 20-60) and "severe" (grades $>60$ ) disease the corresponding proportions of abnormal transfer factor measurements were 15 out of $26(58 \%)$ and seven out of $10(70 \%)$ cases. The sensitivity of gas transfer factor in predicting the presence of mild to moderate emphysema was less in this study than in that of Pare et al, ${ }^{31}$ but the use of a steady state rather than a single breath method may have been responsible for this difference.

Although reduction in single breath gas transfer factor is related to the presence of emphysema and correlates with the more complex measurement $\mathrm{K}$, there are limitations to the use of transfer factor in determining which smokers may have emphysema. Gas transfer factor is influenced by diseases other than emphysema, and, more importantly, it is systematically decreased in most "healthy" smokers (being about $10-20 \%$ less on average than that of nonsmokers). ${ }^{43-47}$ The reason for this general decrease in transfer factor is unknown; but it appears to be a "step" effect, occurring even in young smokers within a year or two of starting smoking, and it may be partly reversible on stopping smoking. ${ }^{4-47}$ Although an asymptomatic increase in alveolar size might explain some of this abnormality in transfer factor, the generalised finding is inconsistent with the relatively small proportion of "healthy" smokers (perhaps $20 \%$ ) who have abnormally increased lung distensibility. ${ }^{48}$ If gas transfer factor is to be used as a screening test for emphysema in smokers, the systematic difference from non-smokers should be allowed for and comparisons should be made with values obtained from "healthy" smokers rather than a nonsmoking population. ${ }^{43}$

The exponential constant $\mathrm{K}$ is at present the optimum lung function test for detecting emphysema during life, and the development of an on line computerised measurement system ${ }^{49}$ has made this approach simpler and more generally applicable than previously. Although pressure-volume curves have been used in several epidemiological studies, ${ }^{4850-52}$ this complex test, which requires the swallowing of an oesophageal balloon, is unlikely to gain general acceptance for screening purposes. As a diagnostic and research tool, however, it has great power to detect "early" emphysematous changes and to discriminate between loss of lung elasticity and increased airway resistance as the principal cause of airflow obstruction in a given individual. ${ }^{25}$ Its wider applica- 
tion might throw more light on the early stages of the development of chronic airflow obstruction.

IAN A GREAVES

Department of Environmental Science and Physiology Harvard School of Public Health Boston, Massachusetts, USA

H JOHN H COLEBATCH
Department of Medicine
University of New South Wales
Prince Henry Hospital
Sydney, Australia

\section{References}

1 Auerbach O, Hammond EC, Garfinkel L, Benante C. Relation of smoking and age to emphysema. $N$ Engl J Med 1972;286:853-7.

2 Auerbach O, Garfinkel L, Hammond EC. Relation of smoking and age to findings in lung parenchyma: a microscopic study. Chest 1974;65:29-35.

3 Mitchell RS, Stanford RE, Johnson JM, Silvers GW, Dart G, George MS. The morphologic features of the bronchi, bronchioles, and alveoli in chronic airway obstruction: a clinicopathologic study. Am Rev Respir Dis 1976;114:137-45.

4 Thurlbeck WM. Chronic airflow obstruction. Philadelphia: WB Saunders, 1976:12-310.

5 Bignon J, Khoury F, Even P, André J, Brouet G. Morphometric study in chronic obstructive bronchopulmonary disease. Am Rev Respir Dis 1969;99:669-95.

6 Kuhn C, Senior RM. The role of elastases in the development of emphysema. Lung 1978;155:185-97.

7 Snider GL. The pathogenesis of emphysema-twenty years of progress. Am Rev Respir Dis 1981;124:321-4.

8 Janoff A. Biochemical links between cigarette smoking and pulmonary emphysema. J Appl Physiol: Respirat Environ Exercise Physiol 1983;55:285-93.

9 Kaplan PD, Kuhr C, Pierce JA. The induction of emphysema with elastase. I-The evolution of the lesion and the influence of serum. J Lab Clin Med 1973;82:349-56.

10 Snider GL, Scherter CB. A one-year study of the evolution of elastase-induced emphysema in hamsters. $J$ Appl Physiol: Respirat Environ Exercise Physiol 1977;43:721-9.

11 Snider GL, Korthy AL. Internal surface area and number of respiratory air spaces in elastase-induced emphysema in hamsters. Am Rev Respir Dis 1978;117:685-93.

12 Greaves IA, Colebatch HJH. Elastic behavior and structure of normal and emphysematous lungs post mortem. Am Rev Respir Dis 1980;121:127-36.

13 Haber PS, Colebatch HJH, Ng CKY, Greaves IA. Alveolar size as a determinant of pulmonary distensibility in mammalian lungs. $J$ Appl Physiol: Respirat Environ Exercise Physiol 1983;54:837-45.

14 Mead J, Turner JM, Macklem PT, Little JB. Significance of the relationship between lung recoil and maximum expiratory flow. J Appl Physiol 1967;22:95-108.

15 Wilson TA, Hyatt RE, Rodarte JR. The mechanisms that limit expiratory flow. Lung 1980;158:193-200.

16 Hogg JC, Macklem PT, Thurlbeck WM. Site and nature of airway obstruction in chronic obstructive lung disease. $N$ Engl J Med 1968;278:1355-60.

17 Woolcock AJ, Vincent NJ, Macklem PT. Frequency dependence of compliance as a test for obstruction in the small airways. $J$ Clin Invest 1969;48:1097-106.

18 Buist AS, Ducic S. Smoking: Evaluation of studies which have demonstrated pulmonary function changes. In: Macklem PT, Permutt S, eds. The lung in transition between health and disease. New York: Marcel Dekker, 1979:271-86.

19 McLean KH. The pathogenesis of pulmonary emphysema. Am J Med 1958;25:62-74.

20 Berend N, Woolcock AJ, Marlin GE. Correlation between the function and structure of the lung in smokers. Am Rev Respir Dis 1979;119:695-706.

21 Gelb AF, Tashkin D, Zamel N. Emphysema, airflow limitation and small airways dysfunction [editorial]. Chest 1982;82:4-5.

22 Macklem PT. Obstruction in small airways - a challenge to medicine. Am J Med 1972;52:721-4.

23 Niewoehner DE, Kleinerman J. Effects of experimental emphysema and bronchiolitis on lung mechanics and morphometry. J Appl Physiol 1973;35:25-31.

24 Park SS, Yoo OH, Janis M, Williams MH. Post mortem evaluation of airflow limitation in obstructive lung disease. J Appl Physiol 1969;27:308-12.

25 Colebatch HJH, Greaves IA, Ng CKY. Pulmonary mechanics in diagnosis. In: de Kock MA, Nadel JA, Lewis CM, eds. Mechanisms of airways obstruction in human respiratory disease: proceedings of the international symposium, Tygerburg, SA, 1978. Cape Town: AA Balkema, 1979:25-47.

26 Hale KA, Ewing SL, Gosnell BA, Niewoehner DE. Lung disease in long-term cigarette smokers with and without chronic airflow obstruction. Am Rev Respir Dis 1984;130:716-21.

27 Berend N. Lobar distribution of bronchiolar inflammation in emphysema. Am Rev Respir Dis 1981;124:318-20.

28 Wright JL, Wiggs BG, Hogg JC. Airway disease in upper and lower lobes in lungs of patients with and without emphysema. Thorax 1984;39:282-5.

29 Buist AS, Nagy JM, Sexton GJ. The effect of smoking cessation on pulmonary function: a 30-month followup of two smoking cessation clinics. Am Rev Respir Dis 1979;120:953-7.

30 Gelb AF, Gold WM, Wright RR, Breech HR, Nadel JA. Physiologic diagnosis of subclinical emphysema. Am Rev Respir Dis 1973;107:50-63.

31 Paré PD, Brooks LA, Bates J, et al. Exponential analysis of the lung pressure-volume curve as a predictor of pulmonary emphysema. Am Rev Respir Dis 1982;126:54-61.

32 Niewoehner DE, Kleinerman J, Liotta L. Elastic behavior of postmortem human lungs: effects of aging and mild emphysema. J Appl Physiol 1968;25:664-71.

33 Berend N, Skoog C, Thurlbeck WM. Pressure-volume characteristics of excised human lungs: effects of sex, age, and emphysema. J Appl Physiol: Respirat Environ Exercise Physiol 1980;49:558-65. 
34 Silvers GW, Petty TL, Stanford RE. Elastic recoil changes in early emphysema. Thorax 1980;35:490-5.

35 Petty TL, Silvers GW, Stanford RE. Functional correlations with mild and moderate emphysema in excised human lungs. Am Rev Respir Dis 1981;124:700-4.

36 Colebatch $\mathrm{HJH}, \mathrm{Ng}$ CKY, Nikov $\mathrm{N}$. Use of an exponential function for elastic recoil. J Appl Physiol: Respirat Environ Exercise Physiol 1979;46:387-93.

37 Colebatch HJH, Greaves IA, Ng CKY. Exponential analysis of elastic recoil and aging in healthy males and females. J Appl Physiol: Respirat Environ Exercise Physiol 1979;47:683-91.

38 Gibson GJ, Pride NB, Davis J, Schroter RC. Exponential description of the static pressure-volume curve of normal and diseased lungs. Am Rev Respir Dis 1979;120:799-811.

39 Cole $\mathrm{P}$, Morrison AS. Basic issues in population screening for cancer. J Natl Cancer Inst 1980;64:1263-72.

40 Knudson J, Bloom JW, Knudson WE, Kaltenborn WT. Subclinical effects of smoking: Physiologic comparisons of healthy middle-aged smokers and non-smokers and interrelationships of lung function measurements. Chest 1984;86:20-9.

41 Pereira RP, Hunter D, Pride NB. Use of lung pressurevolume curves and helium-sulphur hexafluoride washout to detect emphysema in subjects with mild airflow obstruction. Thorax 1981;36:29-37.

42 Thurlbeck WM, Henderson JA, Fraser RG, Bates DV. Chronic obstructive lung disease. Medicine (Baltimore) 1970; 49:81-145.

43 Miller A, Thornton JC, Warshaw R, Anderson H, Teirstein AS, Selikoff IJ. Single breath diffusing capacity in a representative sample of the population of
Michigan, a large industrial state. Predictive values, lower limits of normal, and frequencies of abnormality by smoking history. Am Rev Respir Dis 1983;127:270-7.

44 Martt DM. Pulmonary diffusing capacity in cigarette smokers. Ann Intern Med 1962;56:39-45.

45 Teculescu DB, Stanescu DC. Lung diffusing cpacity: Normal values in male smokers and non-smokers using breath holding techniques. Scand $J$ Respir Dis 1970;51:139-49.

46 Marq M, Minette A. Lung function changes in smokers with normal conventional spirometry. Am Rev Respir Dis 1976;114:723-38.

47 Tockman M, Menkes H, Cohen B, et al. A comparison of pulmonary function in male smokers and exsmokers. Am Rev Respir Dis 1976;114:711-22.

48 Colebatch HJH, Greaves IA, Ng CKY. Pulmonary distensibility and ventilatory function in smokers. Bull Eur Physiopathol Respir 1985;21:439-47.

49 Colebatch $\mathrm{HJH}$, Nail BS, Ng CKY. Computerized measurement of pulmonary conductance and elastic recoil. J Appl Physiol: Respirat Environ Exercise Physiol 1978;44:611-8.

50 Musk AW, Gandevia BH. Loss of pulmonary elastic recoil in workers formerly exposed to proteolytic enzyme (alcalaze) in the detergent industry. $\mathrm{Br} J$ Ind Med 1976;33:158-65.

51 Bouhuys A, Zuskin E. Chronic respiratory disease in hemp workers: a follow-up study, 1967-1974. Ann Intern Med 1976;84:398-405.

52 Gandevia BH. Clinical techniques. In: Weill H, TurnerWarwick M, eds. Occupational lung disorders-research approaches and methods. New York: Marcel Dekker, 1981:11-34. 